lower total pass number than M1 thrombectomy. However, mechanical thrombectomy in the M2 using recent generations of stent retriever technology is associated with higher rates of $\mathrm{SAH}$, likely related to tension on the vessels when pulling through a more tortuous MCA segment.

Disclosures H. Baharvahdat: None. A. Mowla: None. J. Jones: None. Y. Ooi: None. N. Kaneko: None. R. Jahan: None. S. Tateshima: None. V. Szeder: None. M. Nour: None. F. Vinuela: None. G. Duckwiler: None. G. Colby: 2; C; Stryker Neurovascular, Medtronic.

\section{P-012 SHORTER DOOR-IN DOOR-OUT TIME IS ASSOCIATED WITH HIGHER LIKELIHOOD OF ENDOVASCULAR THERAPY AND GOOD OUTCOMES}

${ }^{1} \mathrm{~S}$ Desai ${ }^{*},{ }^{1} \mathrm{~K}$ Shah, ${ }^{2} \mathrm{~T}$ Jovin, ${ }^{1} \mathrm{~A}$ Jadhav. ${ }^{1}$ University of Pittsburgh Medical Center, Pittsburgh, PA; ${ }^{2}$ Cooper University Hospital Neurological Institute, Camden, NJ

\subsection{6/neurintsurg-2019-SNIS.48}

Background and purpose Endovascular therapy is associated with improved clinical outcomes in patients presenting with large vessel occlusions (LVO) however outcomes are typically worse in patients presenting as inter-facility transfers. A further understanding of the sources and impact of transfer delays is essential to improving outcomes in this population.

Methods Data were analyzed from consecutive acute ischemic stroke patients with proximal large vessel occlusions (LVO) transferred to our comprehensive stroke center for consideration of endovascular therapy. The following variables were studied: door-in-door-out time (DIDO), baseline NIHSS/mRS, initial CT ASPECT, site of LVO, treatment and clinical outcome.

Results 309 patients transferred from 14 referral hospitals to our CSC during the study period (January-December 2016). $61(20 \%)$ had a proximal anterior LVO (53) or basilar artery occlusion (8). 40 (66\%) underwent endovascular thrombectomy. 21 (34\%) did not undergo endovascular thrombectomy - due to clinical improvement (33\%), large core or poor ASPECTS (48\%), high baseline disability (5\%) and hemorrhagic transformation (5\%). Median DIDO time in the endovascular thrombectomy group (98.5 minutes) was significantly better ( $p$ value $=0.001$ ) than the Median DIDO time in patients who did not get endovascular thrombectomy (185 minutes). The likelihood decreased by $0.5 \%$ for receiving endovascular therapy and $0.25 \%$ for good outcomes for every minute of DIDO.

Conclusions Shorter DIDO time is associated with higher likelihood of receiving endovascular therapy and good outcomes. DIDO may be used as a clinical performance metric for stroke referring hospitals.

Disclosures S. Desai: None. K. Shah: None. T. Jovin: None. A. Jadhav: None.

\section{P-013 TECHNICAL ASPECTS AND CLINICAL OUTCOME OF ENDOVASCULAR THROMBECTOMY IN OCTOGENARIANS AND NONAGENARIANS: SINGLE CENTER EXPERIENCE}

'S Majidi*, ' IJ Lee, ${ }^{2}$ A Al Balushi, 'J Fifi, 'I Singh. ' $N$ Neurosurgery, Mount Sinai Hospital, New York, NY; ${ }^{2}$ Neurology, Mount Sinai Hospital, New York, NY

10.1136/neurintsurg-2019-SNIS.49
Introduction/Purpose Safety and efficacy of thrombectomy in patients $\geq 80$ years old is not fully understood as this age group is generally underrepresented in major clinical trials. We aimed to review the procedural aspects and clinical outcome of thrombectomy in these patients.

Materials and methods We retrospectively identified all patients $\geq 80$ years old who underwent thrombectomy for acute ischemic stroke with emergent large vessel occlusion (ELVO) in the anterior circulation from January 2014 to December 2018. Demographics, comorbidities, procedural variables, and clinical outcome measures were extracted. Thrombolysis in Cerebral Infarction (TICI) 2B or higher was considered successful reperfusion. Favorable clinical outcome was defined as a 90-day modified Rankin Scale (mRS) score $<3$.

Results A total of 113 patients were identified. The median age for the cohort was 85 years (range: 80-103). Seventythree percent of the patients were women. Forty percent of the patients were white and 59\% had Hispanic ethnicity. A total of 87 patients $(77 \%)$ had internal carotid artery terminus or proximal M1 segment occlusion. Median admission NIHSS score was 18 (IQR: 14-25). Only 27\% of the patients had received intravenous rt-PA. Thirty-two percent of the patients were treated between 6 hours to 24 hours from their time of symptom onset. Successful recanalization was achieved in 101 patients $(89 \%)$ with a mean $( \pm S D)$ groin puncture to recanalization time of $63 \pm 43$ minutes. Monitored anesthesia care (MAC) was used in $78 \%$ of the patients. Groin puncture to recanalization time was 30 minutes shorter in patients under MAC $(54 \pm 36$ vs $85 \pm 50 ; p=0.0006)$; however, no statistically significant difference in the rate of 90-day favorable outcome was observed between the two groups $(23 \%$ vs $20 \%$, $\mathrm{p}=0.77)$. The rate of favorable 90 -day outcome was $22 \%$ and 28 patients $(39 \%)$ had 90 -day mortality.

Conclusions Thrombectomy in octogenarians and nonagenarians is technically feasible and associated with high rate of recanalization. Although the 90-day mortality was elevated in our cohort, the natural history of completed stroke in this population without reperfusion is also high. Despite this finding, nearly one out of four patients in this study had a favorable clinical outcome.

Disclosures S. Majidi: None. J. Lee: None. A. Al Balushi: None. J. Fifi: None. I. Singh: None.

\section{P-014 APPLICATIONS OF A NOVEL MICROANGIOSCOPE FOR NEUROENDOVASCULAR INTERVENTION}

${ }^{1} \mathrm{~V}$ Srinivasan*, ${ }^{1} \mathrm{~T}$ Lazaro, ${ }^{2} \mathrm{P}$ Cooper, ${ }^{2} \mathrm{M}$ Phillips, ${ }^{1} \mathrm{R}$ Garcia, ${ }^{3} \mathrm{~S}$ Chen, ${ }^{1} \mathrm{~J}$ Johnson, 1J Burkhardt, 'D Collins, ${ }^{1} \mathrm{P}$ Kan. ${ }^{1}$ Neurosurgery, Baylor College of Medicine, Houston, TX; ${ }^{2}$ Vena Medical, Baylor College of Medicine, Houston, TX; ${ }^{3}$ Radiology, Baylor College of Medicine, Houston, TX

10.1136/neurintsurg-2019-SNIS.50

Visualization in neuroendovascular interventions relies on biplanar fluoroscopy and digital subtraction. Radiation and contrast-related complications are the two major drawbacks. Angioscopy, direct endoluminal optical visualization, does not require radiation or contrast but has limited utility in neurointerventions due to limitations in size and stiffness. A recently developed microangioscope has the miniaturization and flexibility necessary to navigate small, tortuous intracranial vessels, allowing the practical use of neurovascular angioscopy for the first time. The prototype is a coherent fiber bundle 
microangioscope embedded in a $0.0165^{\prime}$ microcatheter. In human cadaveric experiments, that the microangioscope is compatible with the human intracranial vasculature beyond the Circle of Willis (eg. navigation into and visualization of the M2 origin). In in vivo swine model experiments, the microangioscope has adequate resolution and illumination to identify and differentiate between various intravascular pathologies (eg. red thrombus versus white thrombus). With flow arrest and irrigation, mechanical thrombectomy (both with stent retriever and direct aspiration), coil embolization, stent deployment, and balloon angioplasty were precisely performed under direct visualization with the microangioscope. After deployment, the microangioscope enables direct inspection of devices, providing complementary information to standard angiography. Imaging quality, illumination, and flexibility of the microangioscope progressively improved through modifications to the image bundle. Based on these results, the microangioscope is compatible with the human distal cerebrovasculature; it also provides adequate direct visualization for neurointerventions.

Disclosures V. Srinivasan: None. T. Lazaro: None. P. Cooper: 5; C; Vena Medical, Inc. M. Phillips: 5; C; Vena Medical, Inc. R. Garcia: None. S. Chen: None. J. Johnson: None. J. Burkhardt: None. D. Collins: None. P. Kan: 2; C; Medtronic, Cerenovus.

\section{P-015 LONG-TERM ECONOMIC IMPACT OF THE FIRST PASS EFFECT (FPE) IN THE TREATMENT OF STROKE WITH THE EMBOTRAP II DEVICE (IN ARISE-II)}

${ }^{1} \mathrm{O}$ Zaidat ${ }^{*},{ }^{2} \mathrm{~J}$ Saver, ${ }^{3} \mathrm{H}$ Mattle, ${ }^{4} \mathrm{M}$ Ribo, ${ }^{5} \mathrm{~A}$ Narata, ${ }^{6} \mathrm{~A}$ Yoo, ${ }^{7} \mathrm{H}$ Bozorgchami, ${ }^{8} \mathrm{C}$ Crivera, ${ }^{9} \mathrm{H}$ Cameron, ${ }^{10} \mathrm{~T}$ Andersson. ${ }^{1}$ St. Vincent Mercy Medical Center, Toledo, $\mathrm{OH}_{;}{ }^{2}$ Department of Neurology, University of California, Los Angeles, Los Angeles, CA; ${ }^{3}$ Department of Neurology, University Hospital Bern, Bern, Switzerland; ${ }^{4}$ Department of Neurology, Hospital Vall d'Hebron, Barcelona, Spain; ${ }^{5}$ Service of Radiology and Neuroradiology, University Hospital Tours, Tours, France; ${ }^{6}$ Interventional Neuroradiology/Neuroendovascular Surgery, Texas Stroke Institute, Plano, TX; ${ }^{7}$ Oregon Health and Science University, Portland, OR; ${ }^{8}$ Cerenovus, Johnson and Johnson, IIvine, CA; ${ }^{9}$ Cornerstone Research Group, Burlington, ON, Canada; ${ }^{10}$ Departments of Neuroradiology and Clinical Neuroscience, Karolinska University Hospital and Karolinska Institutet, Stockholm, Sweden

\subsection{6/neurintsurg-2019-SNIS.51}

Introduction The first pass effect (FPE) is the ability to restore near or complete revascularization (modified Thrombolysis in Cerebral Ischemia $[\mathrm{mTICI}] \geq 2 \mathrm{c}$ ) of acutely blocked cerebral arteries in a single thrombectomy device pass. FPE has been shown to be an independent predictor of good functional outcomes (modified Rankin Scale [mRS] $\leq 2$ ), a goal of stroke therapy that impacts healthcare costs, and is associated with reduced 90-day mortality and fewer adverse events. A separate analysis of ARISE-II data showed that the FPE was associated with reduced procedural and in-patient healthcare resource use (length of stay, days in the intensive care unit, standard bed days, and devices used) and accompanying short-term costs; however, the long-term economic impact of achieving the FPE has not been assessed.

Methodology Data were obtained from a single-arm, prospective, multicenter study assessing the EMBOTRAP II device, ARISE-II $(n=227)$. Patients who did not achieve complete revascularization were excluded. Among those who achieved complete revascularization $(\mathrm{mTICI} \geq 2 \mathrm{c})$, the proportion of patients achieving each mRS score was assessed, stratified by the FPE status. Long-term costs per mRS score, obtained from a 2015 U.S. cost-effectiveness analysis that projected annual post-hospitalization inpatient/outpatient and nursing home costs using data from the National Death Index and Centers for Medicare and Medicaid Services (CMS), were applied to all patients. Post-hospitalization costs, in 2018 USD, were then compared between patients that did or did not achieve the FPE and incremental differences were calculated for a 1-year time horizon.

Results In ARISE-II, 76\% of patients $(n=172)$ achieved complete revascularization; among these patients, 53\% achieved the FPE. A significantly higher percentage of patients that achieved the FPE had good functional outcomes vs. those that did not achieve the FPE $(80.5 \%$ vs. $61.0 \%, \mathrm{p}=0.006)$. Estimated annual post-hospitalization costs were lower among patients that achieved FPE vs. those that did not achieve FPE, leading to estimated per-patient cost-savings of $\$ 3,876$ (table 1 ). In the absence of cost data reported in ARISE-II, costs for healthcare resource use were obtained from the literature, which may not be generalizable across settings and is a limitation of this analysis. Additionally, the cost-effectiveness analysis used to inform the long-term costs per mRS score did not report costs for death (i.e., mRS 6), which had a lower incidence among patients who achieved the FPE vs. those who did not achieve the FPE $(5.75 \%$ vs. $14.29 \%)$.

Abstract P-015 Table 1 Per-patient costs for the first year after stroke based on functional outcomes

\begin{tabular}{|c|c|c|c|c|c|c|}
\hline \multirow[t]{2}{*}{$\mathrm{mRS}$} & \multicolumn{2}{|c|}{$\begin{array}{l}\% \text { Achieving } \mathrm{mRS} \\
\text { Level }\end{array}$} & \multirow[t]{2}{*}{$\begin{array}{l}\text { Cost } / \mathrm{mRS} \\
\text { Level }\end{array}$} & \multicolumn{3}{|l|}{ Cost/Patient } \\
\hline & $\begin{array}{l}\text { FPE } \\
(n=91)\end{array}$ & $\begin{array}{l}\text { Not Achieving } \\
\text { FPE }(n=81)\end{array}$ & & FPE & $\begin{array}{l}\text { Not Achieving } \\
\text { FPE }\end{array}$ & Difference \\
\hline 0 & $41.38 \%$ & $19.48 \%$ & $\$ 11,466.92$ & $\$ 14,531.19$ & $\$ 18,407.35$ & $-\$ 3,876.16$ \\
\hline 1 & $21.84 \%$ & $27.27 \%$ & $\$ 11,807.59$ & & & \\
\hline 2 & $17.24 \%$ & $14.29 \%$ & $\$ 13,659.62$ & & & \\
\hline 3 & $9.20 \%$ & $7.79 \%$ & $\$ 23,454.61$ & & & \\
\hline 4 & $2.30 \%$ & $11.69 \%$ & $\$ 47,472.32$ & & & \\
\hline 5 & $2.30 \%$ & $5.19 \%$ & $\$ 69,792.07$ & & & \\
\hline 6 & $5.75 \%$ & $14.29 \%$ & - & & & \\
\hline
\end{tabular}

Conclusion Among patients with final complete reperfusion (mTICI $\geq 2 \mathrm{c})$, achieving FPE may lead to long-term per-patient cost-savings of $\$ 3,876$ in the first year due to improved functional outcomes.

Disclosures O. Zaidat: 1; C; Cerenovus, Stryker, Medtronic, Penumbra, Genentech, Tesla Clinical Trial. 2; C; Cerenovus, Stryker, Medtronic, Penumbra. J. Saver: 2; C; Cerenovus, Stryker, Medtronic, Rapid Medical. H. Mattle: 1; C; Neuravi/Cerenovus. 2; C; Neuravi/Cerenovus. 3; C; Neuravi/Cerenovus. M. Ribo: 1; C; Stryker, Medtronic. 2; C; Cerenovus, Stryker, Medtronic, Anaconda Biomed. 4; C; Anaconda Biomed. A. Narata: None. A. Yoo: 1; C; Cerenovus, Stryker, Medtronic, Penumbra, Genentech. 2; C; Cerenovus, Genentech, Zoll Circulation. 4; C; Insera Therapeutics. H. Bozorgchami: 2; C; Cerenovus, Stryker, Coherex. C. Crivera: 4; C; Johnson \& Johnson. 5; C; Johnson \& Johnson. H. Cameron: 2; C; Employee of Cornerstone Research Group, contracted by Cerenovus. T. Andersson: 2; C; Cerenovus, Anaconda, Medtronic, Ablynx, Amnis Therapeutics, Rapid Medical. 